\title{
Esporte e guerra na Atenas democrática*
}

David M. Pritchard*

PRITCHARD, D.M. Esporte e guerra na Atenas democrática. R. Museu Arq. Etn., 29: 92-104, 2017.

Resumo: Este artigo considera o problema negligenciado do esporte de elite na Atenas Clássica. A democracia ateniense pode ter aberto a política a todos os cidadãos, mas não teve impacto na participação esportiva. Os esportistas desse Estado antigo continuaram a ser recrutados da elite. Portanto, é uma surpresa que os cidadãos que não pertenciam à elite considerassem o esporte como algo positivo e que tenham criado um programa inigualável de festivais esportivos locais em que gastaram uma quantia de dinheiro significativa. Eles também protegiam os esportistas das críticas públicas que normalmente eram direcionadas para a elite e suas atividades conspícuas. $\mathrm{O}$ trabalho dos cientistas sociais sugere que a explicação desse paradoxo se encontra na estreita relação que os atenienses não pertencentes à elite percebiam entre as competições esportivas e a maneira como conduziam a guerra. A conclusão inquietante desta palestra encontra-se na afirmação de que a abertura da guerra aos cidadãos não pertencentes à elite promovida pela democracia ateniense legitimou o esporte de elite.

Palavras-chave: Esporte; Guerra; Democracia; Olimpíadas; Atenas Clássica.

\section{As paixões esportivas dos atenienses}

dèmos ("povo") ateniense despendia
grande quantidade de tempo e dinheiro em competições esportivas. Eles tinham motivo para acreditar que organizavam mais festivais do que qualquer outra cidade-estado grega (Isócrates 4.45;

* Tradução de Camila Diogo de Souza (Museu de Arqueologia e Etnologia, Universidade de São Paulo. <caumilasouza@gmail.com>), Lucia Sano (Escola de Filosofia, Letras e Ciências Humanas, Universidade Federal de São Paulo.<lucia.sano@unifesp.br>).

** Professor Associado da School of Historical and Philosophical Inquiry, Faculty of Humanities and Social Sciences, University of Queensland, Australia. <d.pritchard@uq.edu.au>
[Xenofonte] Ath. Pol. 3.2; Aristófanes Nub. 307-310). A maioria de seus festivais competitivos foi estabelecida nos primeiros 50 anos da democracia (Osborne 1993: 27 28). Competições atléticas eram destaques em 2/3 destes festivais (Osborne 1993: 38; Nielsen 2018: 46-51, 132-136). Eram muito mais frequentes do que os outros tipos de agōnes ("competições"). A popularidade do atletismo, portanto, claramente acompanhou o florescimento da democracia ateniense (Miller 2004: 233).

O programa mais extenso de competições era executado como parte das Grandes Panateneias (Kyle 2014: 160-165). Na década de 380, esse festival quadrienal dedicado à Atena teve competições (agōnes) para indivíduos em 27 eventos esportivos, equestres 
e musicais (Shear 2003). Além disso, as competições em grupos eram organizadas para coros pírricos e ditirâmbicos e para equipes tribais de corredores com tochas, marinheiros e jovens viris. Esses eventos eram mais numerosos que os das antigas Olimpíadas (Miller 2004: 113-129; Shear 2001: 382-384). Outros oito festivais atenienses também incluíam competições esportivas (Pritchard 2013: 93-96).

O dēmos ateniense forçava seus cidadãos da elite a pagar por uma grande parte dos custos operacionais fixos desses festivais esportivos (Xenofonte Oec. 2.6). Os competidores da corrida com tocha das Grandes Panateneias, das Hefesteias e das Prometeias competiam e treinavam como parte de equipes que haviam sido formadas a partir das dez tribos de Clístenes. O custo de treinar cada uma dessas dez equipes recaía sobre um cidadão de elite que servia como gumnasiarkhos ("patrocinador de treinamento esportivo") (Xenofonte Vect. 4.51-2). Um khorēgos ou patrocinador do coro fazia o mesmo para cada um dos coros que competiam nos concursos dramáticos $\mathrm{e}$ ditirâmbicos da cidade-estado (Aristóteles Ath. Pol. 56.2-3; Pritchard 2004). Durante os anos 350 tais liturgias festivais chegaram a um total de 97 por ano, aumentando para 118 nos anos das Grandes Panateneias (Davies 1967: 40).

$\mathrm{Na}$ antiguidade, uma queixa ocasionalmente feita era de que os atenienses gastavam mais em festivais do que em guerras (Demóstenes 4.35-7; Plutarco Mor. 349a). Desde August Böckh, alguns historiadores da Antiguidade viram essa queixa antiga como plenamente justificada (Böckh 1828: v. 1: 280, 360-361; Csapo \& Slater 1995: 141; Kallet 1998: 47; Wilson 2008: 119). É inegável que a democracia ateniense gastava uma grande quantia de dinheiro em festivais da pólis. Mas a comparação cuidadosa de seus gastos reais com eles e o que se gastava com as forças armadas mostra que essa queixa está totalmente errada. De fato, é evidente que a soma que os atenienses gastavam em guerras fez diminuir todas as outras despesas públicas combinadas (Pritchard 2015: 114-115, 2019:
152-157). Por exemplo, os gastos públicos dos anos 420 somente com a guerra foram de 1500 talentos, ou seja, 39 toneladas de prata, em média, por ano (Pritchard 2015: 92-98, 2019: 158-167). Durante a década de 370, a média total de todos os gastos com as forças armadas era de mais de 500 talentos ou 13 toneladas de prata por ano (Pritchard 2015: 99-111).

Apesar disso, o dēmos ateniense ainda dava alta prioridade ao financiamento generoso de seus festivais. Eles gastavam 25 talentos ou 650 quilos de prata em cada celebração das Grandes Panateneias (Pritchard 2015: 28-40). Todo o programa de festivais administrados pela pólis provavelmente consumia nada menos que 100 talentos, ou seja, 2,6 toneladas de prata a cada ano (Pritchard 2015: 40-51). Isso era muito dinheiro: comparável ao custo operacional fixo da própria democracia ateniense e do orçamento anual total de um estado grego de tamanho médio (Pritchard 2015: 49, 51-90). $\mathrm{O}$ dèmos pode ter tratado a guerra como sua principal prioridade pública. Mesmo assim, eles gastavam claramente uma grande quantia em seus festivais esportivos.

A democracia ateniense também atribuiu grande importância à infraestrutura pública para o atletismo (Kyle 2014: 170171). Assim, líderes políticos claramente obtinham vantagem nos agōnes ("debates") por preeminência por cuidar dos campos esportivos públicos do Estado (Kyle 1987: 5692). Por exemplo, no século quinto, Cimon gastou seu próprio dinheiro na construção de pistas de corrida apropriadas e de paisagismo para a Academia (Plutarco Vit. Cim. 13.7). Péricles usou fundos públicos para renovar o Liceu (Harp. s.v. 'Lyceum'). Alcibíades propôs uma lei sobre o Cinosargo (Ath. 234e; IG $\mathrm{i}^{3}$ 134).

Esse apoio público ao atletismo foi também retratado de forma evidente na comédia antiga (Pritchard 2013: 113-120). As comédias que perduraram podem dar a impressão de que simplesmente todas as figuras públicas eram vítimas de abuso cômico. Mas um estudo importante dos alvos dos antigos comediantes por Alan 
Sommerstein mostra que um grupo de atenienses notáveis escapou de tais ataques pessoais: os atletas atenienses (Sommerstein 1996: 331). Além disso, em contraste com o tratamento dado para as outras atividades da elite, os poetas cômicos não submetiam o atletismo a uma paródia bem desenvolvida ou acrítica direta. Eles assumiam de forma explícita que o atletismo era algo inequivocamente bom. Por exemplo, na obra As Nuvens, Aristófanes associou a "velha educação" - da qual o atletismo era o componente principal - a normas de cidadania e virilidade (Aristófanes Nub. 961, 972-84, 1002-32; cf. Ran. 727-33). O Discurso Justo sugere que a educação tradicional floresceu ao mesmo tempo que duas das virtudes fundamentais do Estado grego, isto é, a justiça e a moderação (Aristófanes Nub. 960-2). Ele também alimentou "os homens que lutaram em Maratona” (Aristófanes Nub. 985-6).

$\mathrm{Na}$ democracia ateniense, dramaturgos e oradores públicos geralmente retratavam atletas e atletismo nos mesmos termos positivos (Pritchard 2013: 103-113, 120-130, 138-156). Dramaturgos, evidentemente, eram membros da classe alta (Pritchard 2019: 112 113). Porém, suas peças eram executadas como parte das competições (agōnes) dramáticas de dois festivais patrocinados pela pólis dedicados a Dioniso. O julgamento desses concursos estava oficialmente concentrado nas mãos de juízes selecionados de forma aleatória (Csapo \& Slater 1995: 301-305). Mas a vitória dependia, em última instância, das respostas vocais dos espectadores que eram predominantemente de classe baixa (Demóstenes 18.265; 19.33; 21.226; Platão Resp. 492a; Leg. 659a; Pritchard 2012: 1617). Disso resultou que os poetas cômicos e trágicos tiveram que adaptar suas peças às perspectivas dos cidadãos de classe baixa (Aristóteles Poet. 1453a; Pol. 1341b1020; Platão Leg. 659a-c, 700a-1b). Sob a democracia ateniense, os litigantes e os políticos enfrentavam uma dinâmica de desempenho comparável: seus debates (agōnes) eram decididas pelos votos dos jurados e dos membros da Assembleia e do Conselho provenientes da classe baixa (Pritchard 2019: 114-115). Consequentemente, eles também tiveram que lidar com as percepções dos atenienses pobres (Aristóteles Rh. 1.9.30-1; 2.21.15-16; 2.22.3; Platão Resp. 493d).

Portanto, o tratamento extremamente positivo de atletas e do atletismo na literatura popular ateniense é uma evidência clara da alta estima que a classe baixa ateniense tinha do esporte. A preferência que os cidadãos que não pertenciam à elite demonstravam pelas competições (agōnes) atléticas em seu programa de festivais patrocinado pelo Estado e o cuidadoso gerenciamento da infraestrutura pública dedicada ao atletismo podem ser atribuídos à sua avaliação fortemente positiva dos atletas e do atletismo.

\section{O paradoxo da elite esportiva sob a democracia}

Para os rapazes e jovens atenienses, os treinos em atletismo ocorriam nas aulas regulares da escola do paidotribēs ("professor de atletismo") (Pritchard 2013: 46-53). Isócrates explica como os professores de atletismo instruíam seus alunos nos "movimentos elaborados para a competição" (Isócrates 15.183). Eles os treinavam no atletismo, acostumavam-nos a trabalhar e os compeliam a combinar cada uma das lições que aprendiam (Isócrates 15.184-5). Para Isócrates, esse treinamento transformava os alunos em competidores atléticos competentes, desde que tivessem talento natural suficiente.

Professores de atletismo eram frequentemente representados em textos clássicos ou em cerâmica de figuras vermelhas dando aulas de luta livre ou em outras "modalidades pesadas", boxe e pankration (Aristófanes Eq. 490-2, 1238-9; Platão Alc. I 107e-8e; Grg. 456d-e; Pritchard 2019: 195). Isso não é inesperado, pois muitos desses professores eram donos de uma palaistra ("escola de luta livre") (Ésquines 1.10; Platão Lysis 204a, 207d; Grg. 456c-e). O inesperado é que também os encontramos treinando 
seus alunos em modalidades de esportismo padrão de "pista e campo" do atletismo grego (Fig. 1) (Pritchard 2013: 50). Por exemplo, no Político, Platão descreve como há em Atenas, da mesma maneira que em outras cidades, "muitas sessões de treinamento" supervisionadas "para grupos”, onde são dadas instruções e ponoi ("esforços") são despendidos não apenas em luta livre, mas também "por causa da competição na corrida livre ou em alguma outra modalidade" (Platão Plt. 294d-e; cf. Grg. 520c-d).

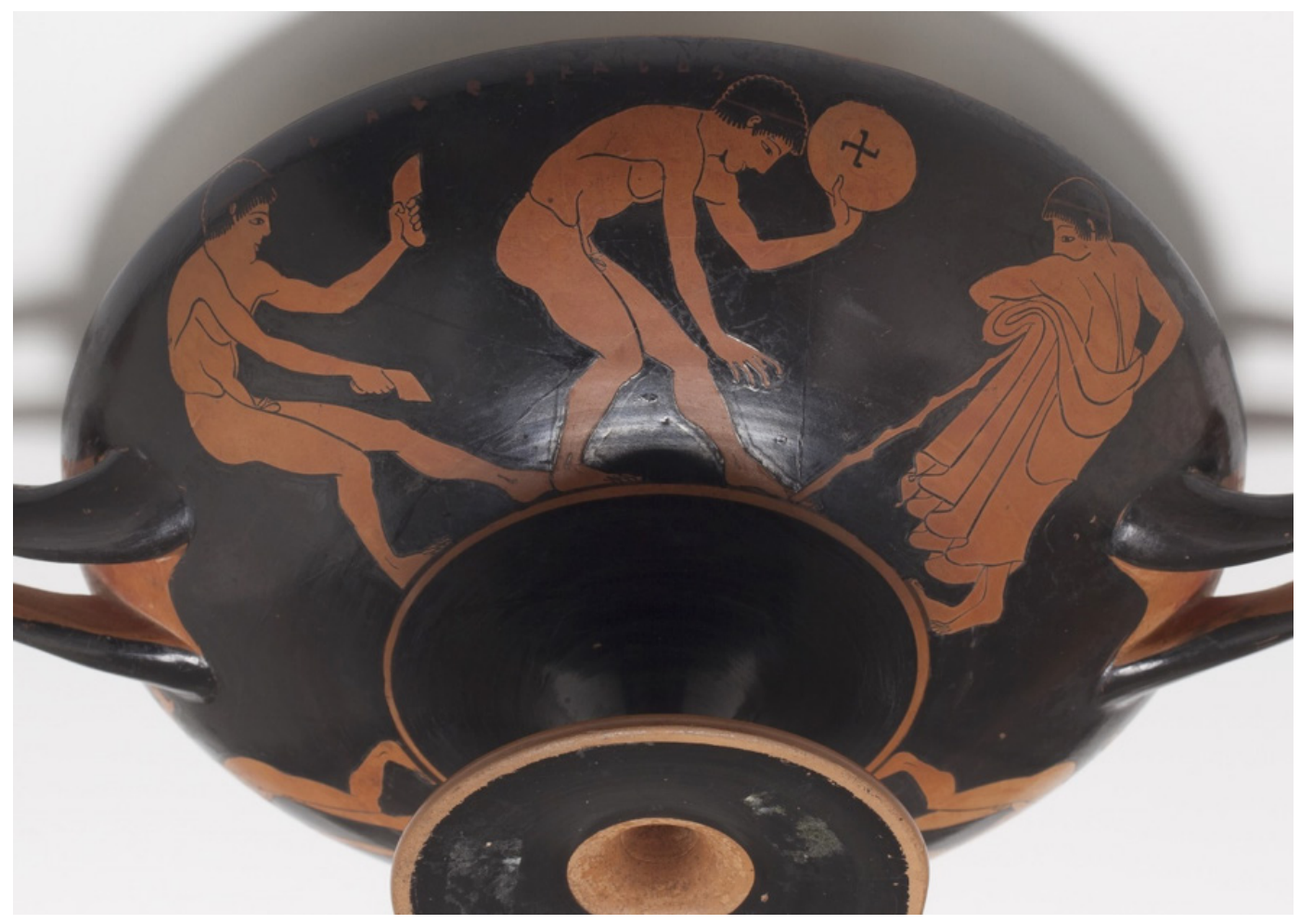

Fig. 1. Professor de atletismo supervisiona dois alunos que estão praticando o skhêmata, um se movimenta para arremessar o disco e o outro para saltar com pesos de mão. Cálice ático de figuras vermelhas, 490-480 a.C., atribuído ao pintor Antiphon. Museum of Applied Arts and Sciences, Sidnei, inv. no. 99/117/1.

Foto: Ryan Hernandez.

É importante observar que a democracia ateniense não financiava nem administrava a educação (Pritchard 2013: 53-58).

Consequentemente, cada família tomava suas próprias decisões sobre quanto tempo seus filhos estariam na escola e se eles seguiriam cada uma das três disciplinas tradicionais de educação: atletismo, música e letras (Platão Alc. I 118d; Cleitophon 407b-c; Prt. 312b, 325e, 326c). Os atenienses entendiam muito bem que o número de disciplinas que um garoto poderia seguir e a duração de sua educação dependiam dos recursos financeiros de sua família (Aristóteles Pol. 1291b28-30, 1317b38-41; Platão Ap. 23c; Prt. 326c; Xenofonte Cyn. 2.1; [Xenofonte] Ath. Pol. 1.5; Jouanna 2017: 147-159). O dinheiro determinava não apenas se uma família poderia pagar as taxas escolares, mas também se eles poderiam dar aos seus filhos o "skhole" ("lazer") que eles precisavam para seguir disciplinas que eram ministradas ao mesmo tempo (Aristófanes Nub. 963-4). Os escritores coevos deixam claro que a maioria 
dos cidadãos pobres não tinha condições de sustentar escravos domésticos suficientes (Aristóteles Pol. 1323a5-7; Heródoto 6.137; Pritchard 2019: 39). Consequentemente, eles confiavam em seus filhos para ajudálos a administrar fazendas ou os negócios (Golden 1990: 34-36). Esses escritores também estavam cientes de como esse trabalho infantil restringia as oportunidades educacionais dos meninos (Isócrates 7.43-5; 14.48; Xenofonte Cyn. 8.3.37-9).

Na obra Sport, democracy and war in Classical Athens (Esporte, democracia e guerra na Atenas Clássica), eu reúno as evidências que demostram como - enquanto resultado de tais barreiras socioculturais - as famílias atenienses pobres deixavam de lado a música e o atletismo (Pritchard 2013: 58-83). Eles enviavam seus filhos apenas para as lições do professor de letras, pois acreditavam que elas eram as mais úteis para a instrução moral e prática. Dessa forma, eram apenas meninos ricos que recebiam treinamento em cada uma das três disciplinas da educação. Como o povo ateniense acreditava veementemente que o treinamento no atletismo era indispensável para um desempenho digno de crédito (Ésquines 3.179-80; Ésquines fr. 78a.34-5 Snell, Kannicht \& Radt; Isócrates 16.32-3; Platão Leg. 807c), meninos e jovens de classe baixa não eram nem incentivados a entrar em competições esportivas. Portanto, na democracia mais desenvolvida dos tempos pré-modernos, os atletas continuavam a ser predominantemente formados - e é possível que até exclusivamente - pela classe alta do Estado (Pritchard 2010: 3-4).

Havia, é claro, outras atividades na Atenas Clássica, como o "simpósio", uma festa onde se ia beber, a homossexualidade pederástica, a liderança política e a equitação, que também eram de domínio exclusivo dos ricos (Pritchard 2013: 130-131, 2019: 62-63). No entanto, essas atividades da classe alta eram diferentes do atletismo em um aspecto crítico: elas eram regularmente criticadas na comédia antiga e nos outros gêneros da literatura popular ateniense. Os atenienses pobres esperavam, um dia, desfrutar do estilo de vida dos ricos
(Aristófanes Av. 592-600, 1105-8; Plut. 133 4; Thesm. 289-90; Vesp. 708-11). Porém, eles ainda tinham problemas com as atividades exclusivas dessa classe social. Cidadãos ricos, por exemplo, eram criticados por seu prazer excessivo em relação a dois elementos do symposion ("banquete"): álcool e prostitutas (Ésquines 1.42; Aristófanes Eccl. 242-4; Eq. 92-4; Vesp. 79-80; Av. 285-6; Ran. 715, 739-40). O dèmos ateniense acreditava que os gastos com tal festa eram bancados às custas da capacidade de um cidadão rico de pagar pelas liturgias dos festivais e seus outros impostos (Aristófanes Ran. 431-3, 1065-8; Demóstenes 36.39; Lísias 14.23-5; 19.9-11; Roisman 2005: 89-92).

O dēmos da Atenas Clássica aparentemente nunca chegou a condenar completamente a pederastia (Pritchard 2013: 131-133). Caso contrário, é difícil explicar por que os políticos ocasionalmente utilizavam tal atividade como metáfora para descrever comportamentos políticos que eles consideravam positivos (Aristófanes Eq. 730-40; Tucídides 2.43.1). No entanto, o julgamento que os atenienses de classe baixa faziam dessa homossexualidade pederástica era amplamente negativo, pois os oradores públicos - juntamente com os poetas cômicos e trágicos - usualmente retratavam o amor pederástico como fonte de ansiedade, associando-o a vícios estereotipados da classe alta, deturpavam a relação entre erastēs ("amante") e erōmenos ("amado"), representando-a como uma relação entre cliente e prostituto (Aristófanes Plut. 127-42; Hubbard 1998). Assim, parece que o atletismo não era apenas altamente valorizado, mas também apoiado pela democracia ateniense. Além disso, ele escapou da crítica persistente das atividades da classe alta na cultura popular ateniense (Pritchard 2013: 136-138). Por que isto aconteceu, tem sido uma questão sem resposta.

\section{Ideias populares e teorias modernas}

Obviamente que têm havido ideias populares divergentes sobre o impacto do 
esporte na guerra (Pritchard 2013: 20-30). Essas ideias levaram a uma ampla gama de teorias modernas sobre essa relação. $O$ Duque de Wellington pode nunca ter dito - apesar da fama que lhe é atribuída por ele ter dito - que a Batalha de Waterloo foi vencida nos campos de jogos de Eton. Porém, é verdade que, a partir do século XIX, os meninos das escolas particulares da elite inglesa foram obrigados a praticar esportes organizados em razão de sua moralidade (Guttmann 2001: 9). Esportes, como rúgbi, críquete e atletismo, eram geralmente vistos como capazes de ensinarlhes os valores pessoais que eles precisavam para gerir os negócios, administrar o Império Britânico e lutar pelo rei e pelo país. As elites contemporâneas na Europa e na América do Norte de fato viram esses esportes escolares como uma razão secreta para o sucesso econômico e o império mundial da GrãBretanha. Consequentemente, eles procuraram estabelecer clubes amadores para praticá-los, na esperança de aumentar a fortuna de seus próprios países. Esses clubes rapidamente formaram organizações nacionais. A partir deles, foram formados corpos esportivos internacionais. Um bom exemplo é o Comitê Olímpico Internacional (International Olympic Committee). O COI estabeleceu-se em Paris em 1894 (Guttmann 2001: 12-20). Como principal proponente de seu estabelecimento, Pierre de Coubertin acreditava que reviver os Jogos Olímpicos uniria os países hostis e estimularia a paz mundial (Guttmann 2001: 8-9).

Partindo de sua própria experiência negativa em uma escola privada da elite inglesa, George Orwell chegou a conclusões diferentes sobre o impacto do esporte na guerra, em uma coluna de jornal publicada em dezembro de 1945. A União Soviética havia enviado pouco tempo antes para a Inglaterra um dos seus principais times de futebol para jogar contra clubes locais ostensivamente, de modo a manter relações pacíficas entre os dois aliados do período da guerra. Mas as coisas - segundo dizem - não correram de acordo com o planejado: após controvérsias sobre seleção de equipes e de arbitragem, confrontos violentos no campo de futebol e comportamento antidesportivo da parte dos torcedores ingleses, a equipe soviética deixou a Inglaterra prematuramente depois de apenas dois jogos. Para Orwell, esse desastre do Dínamo de Moscou confirmou o ceticismo sobre o potencial do esporte internacional na promoção da coexistência pacífica (Orwell 1973: 41-42). "Mesmo se", Orwell escreveu, "não se soubesse por meio de exemplos concretos (os Jogos Olímpicos de 1936, por exemplo), que competições esportivas internacionais levam a orgias de ódio, pode-se deduzi-lo dos princípios gerais".

Orwell sugere que a ligação de uma equipe esportiva a "alguma unidade maior" inevitavelmente desperta "os instintos mais combativos". No nivel internacional, isso encoraja os espectadores - juntamente com nações inteiras - a acreditar que "correr, pular e chutar uma bola são testes de virtude nacional" e permite o "vencer a qualquer custo". Como resultado, Orwell conclui: "O esporte sério não tem nada a ver com fair play. Está ligado ao ódio, à inveja, à arrogância, ao desrespeito a todas as regras e ao prazer sádico em testemunhar violência: em outras palavras, é a guerra sem o tiroteio" (Orwell 1973: 42).

Desnecessário dizer que o Comitê

Olímpico Internacional nunca aceitou qualquer crítica a sua crença na promoção da paz pelo esporte. Os sucessores de De Coubertin continuaram a acreditar que a promoção da paz mundial e a reconciliação das nações em guerra eram os principais propósitos das Olimpíadas modernas (Guttmann 2001: 1-2, 99, 181). Ao fazê-lo, no entanto, eles nunca explicaram exatamente como a participação esportiva alcança tal resultado de "trazer a paz". Felizmente, ideias coerentes sobre o impacto do esporte no comportamento agressivo há muito tempo têm sido usadas nas culturas populares do mundo ocidental. Por exemplo, treinadores de futebol americano acreditam que a prática de esportes é uma maneira segura de reduzir a agressão, que reforça valores socialmente construtivos, tal como trabalho em equipe, e que, portanto, reduz a probabilidade de guerra (Sipes 1973: 66-67). Jornalistas esportivos até acreditam que 
simplesmente assistir a esportes pode reduzir a agressão (Guttmann 1998: 18).

Dentro das ciências sociais, essa visão popular do esporte como uma válvula de segurança para a agressividade foi integrada em diferentes teorias da catarse. Essas teorias remontam a Freud e, em última análise, a Aristóteles. Possivelmente, a mais influente delas é o chamado "modelo catártico de descarga pulsional”. Este modelo foi inventado por Konrad Lorenz nos anos 1960 (Lorenz 1966). Como pioneiro da Etologia, Lorenz defendeu que a agressão é um impulso inato. Ele vai se acumulando constantemente em animais ou seres humanos como tensão agressiva. Para Lorenz, esse acúmulo é semelhante ao funcionamento de uma caldeira a vapor. A tensão agressiva aumenta até o ponto em que deve ser liberada como uma explosão descontrolada ou em uma série de descargas controladas. Consequentemente, a agressividade pode ser liberada com segurança por meio de atividades socialmente aceitáveis, como o esporte (Lorenz 1966: 231-233, 242-243).

Esse modelo "catártico de descarga pulsional" ainda é usado, às vezes, pelos historiadores do esporte. Contudo, ele está atualmente totalmente desacreditado nas ciências sociais. Por sua vez, os psicólogos sociais demostraram que o que o modelo de Lorenz prediz sobre o esporte competitivo e a agressão são totalmente infundados: longe de haver uma relação inversa, o esporte claramente aumenta a agressividade. Por exemplo, um estudo de psicologia social de estudantes da Universidade da Indiana descobriu que o nível de agressão não provocada entre os jogadores do futebol americano era muito maior do que daqueles que não praticavam esporte algum (Zillmann, Johnson \& Day 1974: 146-147, 150).

O esporte parece ter um impacto semelhante nos espectadores. Entrevistas em um jogo de futebol americano ArmyNavy realizado na Filadélfia mostraram que os espectadores do sexo masculino estavam muito mais agressivos depois do evento, independentemente de seu time ter ganhado ou perdido (Goldstein \& Arms 1971:
88-89). Um estudo similar obteve os mesmos resultados com espectadores canadenses de hóquei no gelo: assistir ao jogo aumentou significativamente a agressividade geral não somente nos homens, mas também nas mulheres (Arms, Russell \& Sandilands 1979: 278-279). Além disso, suas capacidades de interagir cooperativamente com os outros diminuíram durante o ato de assistir ao jogo. Esses resultados, conclui o estudo, "colocam em questão a suposição de que os eventos esportivos são necessariamente ocasiões sociais ricas, em que a boa vontade e as relações interpessoais calorosas são estimuladas".

Outra disciplina das ciências sociais que desafiou a teoria da "modelo catártico de descarga pulsional" é a antropologia. Os antropólogos assumem que a agressão humana não é uma qualidade inata. Pelo contrário, é algo que é aprendido ou, pelo menos, inteiramente moldado por fatores socioculturais (Sipes 1973: 66-67). Alguns antropólogos também assumem que valores comuns caracterizam atividades sociais díspares e que padrões gerais de uma cultura tendem a se apoiar mutuamente. Claude Lévi-Strauss, por exemplo, presumiu que diferentes estruturas de significado em uma cultura tendem a "se sobrepor, cruzar e reforçar uma a outra" (Morley 2004: 123). Finalmente, Günther Lüschen a partir de estudos de caso antropológicos afirma que "o esporte é de fato uma expressão do sistema sociocultural em que ele ocorre" (Lüschen 1970: 87). Para Lüschen, o esporte não apenas evoca as normas e valores de uma sociedade, mas também "socializa" em sua direção. O esporte ajuda, portanto, a articular e legitimar as estruturas sociais (Lüschen 1970: 93-94).

Em um aclamado estudo, Richard Sipes reúne tais suposições em uma nova teoria sobre o impacto do esporte na guerra. Ele denomina sua teoria de modelo de padrão cultural (Sipes 1973: 64-65). Este modelo considera a "intensidade e configuração" da agressão como "características predominantemente culturais". Ele pressupõe "uma tensão direcionada à consistência em cada cultura, com valores e padrões de comportamento semelhantes, como 
a agressividade, tendendo a se manifestar em mais de uma área de cultura" (Sipes 1973: 65). Consequentemente, comportamentos e padrões culturais "relativos a guerras e esportes bélicos tendem a se sobrepor e reforçar a presença um do outro" (Sipes 1973: 65, grifo do autor). O modelo de Sipes prevê uma relação direta entre esportes bélicos e guerra: esportes bélicos são mais prováveis de ocorrer em sociedades guerreiras do que em sociedades pacíficas.

\section{A sobreposição cultural entre esporte e guerra}

Os atenienses do período clássico pensavam no atletismo e na batalha a partir de um conjunto comum de conceitos. Nenhum escritor antigo comentou a respeito dessa sobreposição cultural. Porém, o modelo de padrão cultural de Sipes sugere que essa sobreposição pode explicar o paradoxo do esporte de elite na democracia ateniense. A superposição cultural mais importante era de que a batalha e uma competição atlética qualquer eram ambas consideradas um agōn - isto é - uma disputa decidida por regras mutuamente acordadas (Pritchard 2013: 165-176). Nos últimos 20 anos, as democracias ocidentais - incluindo a minha por vezes travaram guerras contrariando a lei internacional. Portanto, pode ser fácil esquecer que a guerra no mundo ocidental já foi regulada por convenções amplamente discutidas e vista como uma maneira legítima de resolver disputas entre estados-nação. A batalha hoplítica usual da Grécia Clássica não constituiu uma exceção, sendo como era para citar Jean-Pierre Vernant - "um teste tão limitado por regras quanto um torneio" (Vernant 1988: 38).

Consequentemente, um estado grego informava outro sobre a sua intenção de atacálo enviando um arauto (Tucídides 1.29.1). De comum acordo, seus exércitos se reuniam na topografia que melhor se adequava à guerra terrestre para os gregos: uma planície agrícola (Heródoto 7.9; Plutarco Mor. 193e). Depois de horas de luta corpo-a-corpo, o momento decisivo era a trope ("virada"), quando os hoplitas de um lado se separavam e corriam para se salvar (Eurípedes Heracl. 841-2). Os vencedores os perseguiam apenas por uma curta distância antes de se voltarem para o que tinham que fazer no campo de batalha. Lá, eles coletavam os corpos de seus companheiros mortos, despojavam os corpos do inimigo e usavam algumas das armas e armaduras que haviam capturado para montar um tropaion ("troféu") no local exato em que o tropē havia ocorrido (Ésquines Sept. 277, 954). Quando os derrotados tinham tempo de se reagrupar, eles enviavam um arauto aos que controlavam o campo de batalha para pedir uma trégua a fim de recuperar seus mortos (Plutarco Vit. Nic. 6.5-6; Tucídides 4.44, 97). O costume ditava que os vencedores, de maneira honrosa, não poderiam recusar esse pedido. Contudo, se reconhecia no pedido de trégua uma admissão decisiva de derrota (Heródoto 1.82; Tucídides 4.44.5-6; Xenofonte Hell. 3.5.22-5; 7.5.26).

Para os atenienses do período clássico, os agōnes ("disputas") do atletismo e da guerra também testavam a fibra moral e as capacidades físicas individuais dos esportistas e soldados (Pritchard 2013: 176-188). Ambos eram considerados como atividades que envolviam ponoi ("esforço físico") e kindunoi ("perigos") (Ponoi em esportes: Eurípedes Alc. 1025-6; Píndaro Isthm. 4.47; 5.22-5; Ol. 6.9-11; 10.22-3; Nem. 6.23-4. Ponoi em batalhas: Aristófanes Ach. 695-7; Eq. 579; Eurípides Supp. 373; Tucídides 2.38.1. Kindunoi: Demóstenes 60.3-5; Lísias 2.20, 43, 50-1; Platão Menex. 239a-b). Essa visão popular do atletismo como perigoso era bem justificada. Por exemplo, as amarras das mãos e dos braços de um boxeador grego foram projetadas - como as soqueiras - para proteger suas mãos e ferir seu oponente, enquanto o vencedor de uma luta de boxe surgia apenas quando um boxeador desistia ou era derrubado inconsciente. Os boxeadores eram, de fato, ocasionalmente mortos (Pausânias 6.4.2; 8.40.3-5). As representações frequentes deles em vasos de figuras negras e vermelhas mostram o sangue escorrendo de seus rostos (Fig. 2). 


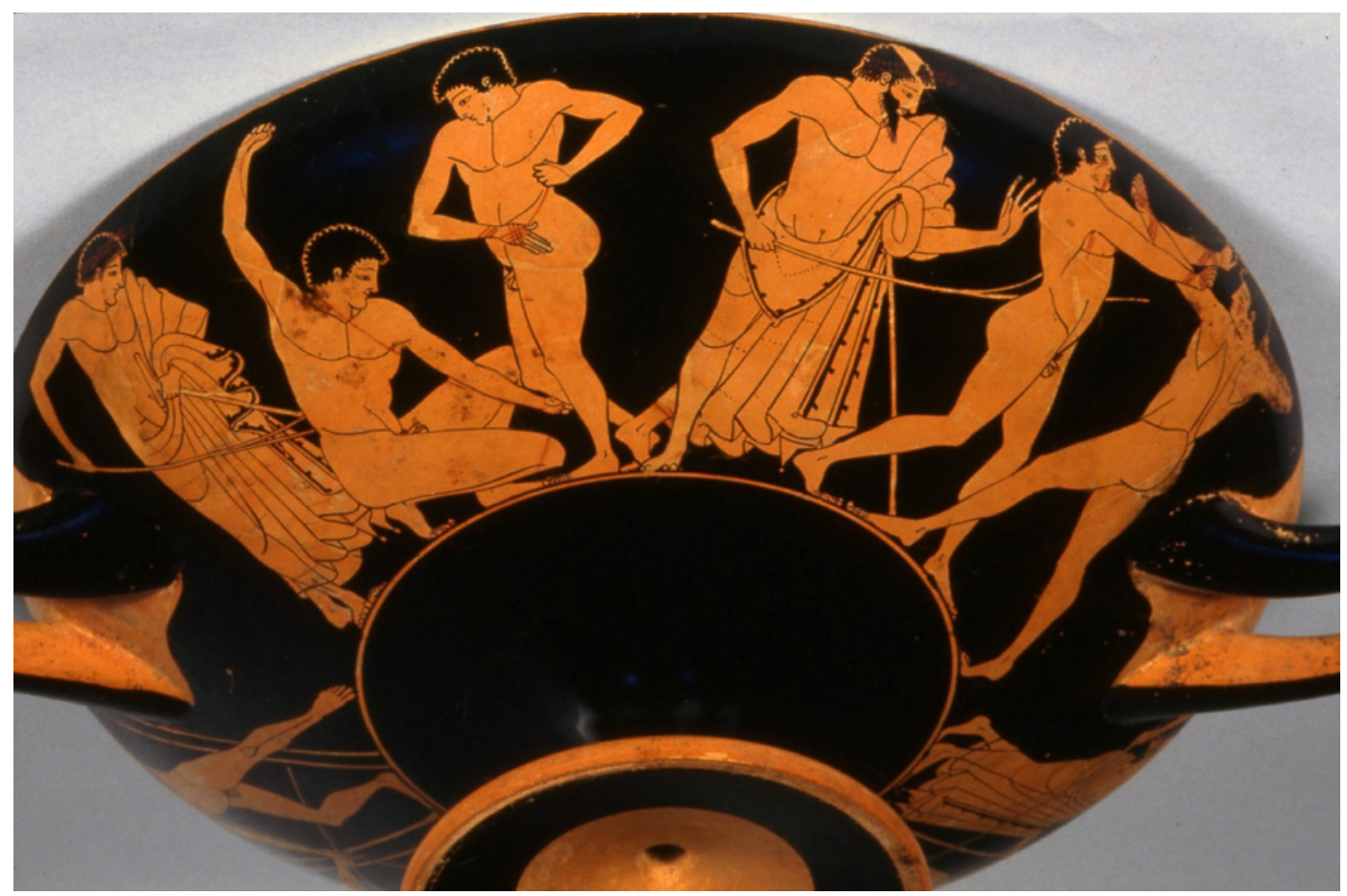

Fig. 2. Dois pugilistas amarram suas mãos com himantes ("soqueiras de couro"), enquanto outros dois ferem os rostos um do outro em uma luta de boxe. Cálice ático em figuras vermelhas, 490 a.C., atribuído ao pintor Triptolemos. Toledo Museum of Art, Toledo (Ohio), inv. no. 1961.26.

Fonte: Toledo Museum of Art, Toledo (Ohio).

Os atenienses do período clássico acreditavam que a vitória também se devia à aretē ("bravura") dos atletas (Bowra 1964: 171-172) e soldados (Demóstenes 60.21; Lísias. 2.4-6, 20, 64-5; Platão Menex. 240d) e à kudos ("ajuda divina") dos deuses e semideuses protetores da pólis (Sófocles El. 697-9; Bowra 1964: 173-174; Pritchard 2019: 209-211. Kudos para os soldados: Ésquilo Sept. 271-80; Aristófanes Vesp. 1085; Lísias 2.39; Tucídides 6.32.1). Em contraposição, a derrota de um esportista (Xenofonte Mem. 3.7.1; Bowra 1964: 182-183) e de um soldado (Demóstenes 60.21; Eurípedes Or. 1475-88; Lísias 2.64-5) era atribuída à sua covardia e considerada uma fonte de intensa vergonha pessoal.

Essa sobreposição cultural entre as agōnes (competições/disputas) do esporte e da guerra resultou em duas formas distintas de avaliação que os atenienses de classe baixa tinham do atletismo. A primeira dessas formas estava intimamente ligada à posição do polemos ("guerra") na Atenas democrática (Pritchard 2019: 153-157). Os atenienses do período clássico intensificaram e transformaram a condução da guerra (Pritchard 2010: 5-7, 15-27, 2019: 4-9). Frequentemente atacavam outras democracias e matavam dezenas de milhares de companheiros gregos. No momento em que a democracia ateniense consolidou-se plenamente, a guerra havia dominado suas políticas e suas vidas pessoais. A guerra consumia mais dinheiro do que todas as outras atividades públicas combinadas, era travada com mais frequência do que nunca e constituía o principal tema do debate político (Pritchard 2010: 6). Os cidadãos da classe baixa valorizavam mais a guerra do que qualquer outra atividade secular. Eles viam a si próprios como mais corajosos no campo de batalha do que o resto dos gregos, seus motivos para travar guerras como sempre justos, e a história de seu 
Estado - desde a era dos heróis - como uma série de vitórias militares quase ininterruptas (Demóstenes 60.11; Lísias 2.55; Eurípedes Supp. 306-42, 378-80; Crowley 2012: 88-92)1.

$\mathrm{Na}$ Atenas democrática, a guerra era mais proeminente como atividade pública do que o atletismo. Os atenienses do período clássico - é verdade - devotavam muito tempo e dinheiro a agōnes atléticos. Mas eles se dedicavam consideravelmente mais a suas forças armadas e campanhas militares verdadeiras. Tais campanhas normalmente envolviam milhares de hoplitas e marinheiros não pertencentes à elite. No entanto, a concepção dessas duas atividades como comparáveis significava que o atletismo estava intimamente associado a uma parte dos negócios vitais da democracia ateniense, que era mantida na mais alta estima possivel. As outras atividades conspícuas dos ricos careciam de uma conexão tão próxima com o polemos. Isso significou que a sobreposição cultural entre esporte e guerra deu ao atletismo uma vantagem real sobre elas nas avaliações que o dēmos ("o povo") fazia regularmente sobre o estilo de vida da elite.

\section{Conclusões: a democratização da guerra}

A Atenas do século V estendeu o serviço militar e suas representações tradicionais a todos os estratos da classe mais baixa. Antes da democracia ateniense, a guerra era, em grande parte, uma atividade de elite. As guerras eram travadas com pouca frequência. Elas eram iniciadas de forma privada por líderes de facções da classe alta (Plutarco Vit. Sol. 9.2-3; Pritchard 2019: 5-6). Os hoplitas de cada campanha eram numerados às centenas e não aos milhares. Eles vinham predominantemente da classe alta de Atenas (Singor 2009). Como eles representavam a sua infantaria pode ser visto na cerâmica arcaica de figuras negras e vermelhas. As cenas militares nesses objetos foram analisadas de forma excelente por François Lissarrague. Essas cenas mostram como os atenienses de classe alta se basearam nos valores e nos conceitos

1 Esta é a imagem do ato de guerrear ateniense na oração fúnebre e na tragédia. da poesia épica para glorificar sua própria vida militar (Lissarrague 1990: 233-240). Isso pode ser visto claramente nas cenas de um hoplita morto em ação ou de seu cadáver sendo levado de volta para Atenas. Os heróis de Homero discutem como eles vão obter o renome imperecível e a memória imperecível de sua juventude morrendo bravamente em batalha (Homero Il. 12.318-28; 22.71-3, 304 5; cf. 22.362-4; Loraux 2018). Com sua "bela morte”, um herói obtém uma confirmação eterna de sua aretē, que se reflete na beleza de seu cadáver. Os pintores às vezes representam essa aretē do hoplita abatido pintando um leão (Lissarrague 1990: 71-96). O leão era um dos animais usados por Homero para representar a excelência marcial de um herói (Homero $I l$. 5.782; Od. 8.161; 11.611). Os pintores áticos evocavam a conquista da bela morte dos heróis dando apenas ao hoplita cabelos longos, o que é, novamente, uma característica dos heróis na poesia épica (Homero Il. 3.43; 2.443, 472; 18.359).

A criação de um exército publicamente controlado de hoplitas como parte das reformas que Clístenes introduziu no final do século VI a.C., a expansão massiva da marinha pública e a introdução do pagamento pelo serviço militar abriram a guerra, assim como a política, para grandes números de cidadãos que não eram da elite (Pritchard 2013: 200-203). Devido ao poder real que essa classe social exercia nos fóruns políticos e legais da democracia ateniense e também em seus concursos dramáticos, oradores públicos e dramaturgos acharam necessário representar as experiências desses novos hoplitas e marinheiros com a explicação moral tradicional da vitória no campo esportivo ou de batalha (Ésquilo Pers. 357-60, 386-401; Aristófanes Vesp. 684-5; Tucídides 2.86; Pritchard 2018, 2019: 109-137).

Essa democratização ideológica da guerra pode ser claramente observada no funeral público dos atenienses mortos em guerras (Arrington 2015). As cinzas desses combatentes mortos eram colocadas em 10 urnas de cipreste (um para cada tribo) e exibidos no centro cívico de Atenas (Tucídides 2.34). No dia do funeral, eles eram levados para o cemitério público, 
onde eram colocados em uma "bela e grandiosa tumba" (Platão Menex. 234c). Essas tumbas eram às vezes adornadas com estátuas de leões e imagens de soldados matando inimigos que evocavam a aretē daqueles que foram enterrados (Low 2010: 342-350). Elas também tinham epigramas, explicando que os mortos haviam colocado sua aretē além da dúvida, deixando para trás uma memória eterna de coragem (IG $\mathrm{i}^{3}$ $1179.3,8-9 ; 1162.48)$. Por fim, cada túmulo mostra uma lista completa das vítimas do ano incluindo marinheiros atenienses - organizada por tribos ( $\mathrm{IG} \mathrm{i}^{3}$ 1142-93; Pritchard 1999: 234-240). A oração fúnebre tradicionalmente realizada depois do enterro sempre mostrava como os mortos de guerra haviam garantido "a morte mais bela": ao caírem em batalha pelo estado, obtinham um renome imperecível e uma lembrança imperecível não apenas pela sua aretē, mas também pela sua juventude (Demóstenes 60.32-3; Hipérides 6.27-30; Lísias 2.78-81; Platão Menex. 247c, 248c; Tucídides 2.43-4).

Essa democratização prática e ideológica da guerra criou uma segunda forma da sobreposição cultural entre esporte e guerra impactar positivamente no esporte. O dēmos ateniense não apenas associava o atletismo com a altamente valorizada e proeminente atividade pública da guerra, mas também tinha uma forte ligação pessoal com as atividades que os atletas de fato praticavam.

Eles podiam ver como os esportistas exibiam sua aretē e suportavam kindunoi e ponoi da mesma forma como eles mesmos faziam quando lutavam por Atenas. Juntas, essas duas maneiras explicam por que os atenienses que não pertenciam à elite valorizavam tanto o atletismo e os atletas, protegendo-os ambos das críticas públicas e mostrando uma forte preferência por competições (agōnes) atléticas em relação aos outros tipos de competições em seu programa de festivais. Em conclusão, as mudanças que os atenienses que não pertenciam à elite realizaram na condução da guerra legitimaram e sustentaram o esporte de elite.

\section{Agradecimentos}

Este artigo é resultado de uma conferência proferida no Museu de Arqueologia e Etnologia da Universidade de São Paulo (MAE/USP) e na Universidade Federal de São Paulo (UNIFESP) em 2018. Agradeço sinceramente a Camila Diogo de Souza e Lucia Sano por me convidarem para palestrar em suas respectivas universidades. Sou imensamente grato à Camila pela excelente tradução do artigo para o português.

PRITCHARD, D.M. Sport and war in democratic Athens. R. Museu Arq. Etn., 29: 92-104, 2017.

Abstract: This article considers the neglected problem of elite sport in classical Athens. Athenian democracy may have opened up politics to every citizen but it had no impact on sporting participation. This ancient state's sportsmen continued to be drawn from the elite. Therefore, it comes as a surprise that non-elite citizens judged sport to be a very good thing and created an unrivalled program of local sporting festivals on which they spent a staggering sum of money. They also shielded sportsmen from the public criticism that was otherwise normally directed towards the elite and its conspicuous activities. The work of social scientists suggests that the explanation of this paradox lies in the close relationship that non-elite Athenians perceived between sporting contests and their own waging of war. The disturbing conclusion of this talk is that it was Athenian democracy's opening up of war to non-elite citizens that legitimized elite sport.

Keywords: Sport; War; Democracy; Olympics; Classical Athens. 


\section{Referências bibliográficas}

Arms, R.L.; Russell, G.W.; Sandilands, M.L. 1979. Effects on hostility of spectators of viewing aggressive sports. Social Psychology Quarterly 42: 275-279.

Arrington, N. 2015. Ashes, images and memories: the presence of the war dead in fifth-century Athens. Oxford University Press, Oxford.

Balot, R.K. 2014. Courage in the democratic polis: ideology and critique in Classical Athens. Oxford University Press, Oxford.

Böckh, A. 1828. The public economy of Athens. Tradução: George Cornewall Lewis. J. W. Parker, London, 2 volumes.

Bowra, C.M. 1964. Pindar. Oxford University Press, Oxford.

Crowley, J. 2012. The psychology of the Athenian hoplite: the culture of combat in Classical Athens. Cambridge University Press, Cambridge.

Csapo, E.; Slater, W.J. 1995. The context of ancient drama. University of Michigan Press, Ann Arbor.

Davies, J.K. 1967. Demosthenes on liturgies: a note. JHS 87: 33-40.

Golden, M. 1990. Children and childhood in Classical Athens. JHU Press, Baltimore.

Goldstein, J.H.; Arms, R.L. 1971. Effects of observing athletic contests on hostility. Sociometry 34: 83-90.

Guttmann, A. 1998. The appeal of violent sports. In: Goldstein, J. (Ed.). Why we watch: the attractions of violent entertainment. Oxford University Press, Oxford, 7-26.

Guttmann, A. 2001. The Olympics: a history of the modern games. 2. ed. University of Illinois Press, Urbana.

Hubbard, T.K. 1998. Popular perceptions of elite homosexuality in Classical Athens. Arion 6: 48-78.
Jameson, M. 1980. Apollo Lykeios in Athens. Archaiolognosia 1: 213-236.

Jouanna, D. 2017. L'enfant grec au temps de Périclès. Realia; Les Belles Lettres, Paris.

Kallet, L. 1998. Accounting for culture in fifth-century Athens. In: Boedeker, D.; Raaflaub, K.A. (Eds.). Democracy, empire, and the arts in fifth-century Athens. Havard University Press, Cambridge, 43-58.

Kyle, D.G. 1987. Athletics in Ancient Athens. E. J. Brill, Leiden.

Kyle, D.G. 2014. Sport, society and politics in Athens. In: Kyle, D.G.; Christesen, P. (Eds.). Sport and spectacle in the Greek and Roman world. WileyBlackwell, Chichester, 159-175.

Lissarrague, F. 1990. L'autre guerrier: archers, peltastes, cavaliers dans l'imagerie attique. La Découverte École Française de Rome, Paris; Rome.

Loraux, N. 2018. The "beautiful death" from Homer to democratic Athens. Tradução: David M. Pritchard. Arethusa 51: 73-89.

Lorenz, K. 1966. On aggression. Tradução: Marjorie K. Wilson. Routledge, New York.

Low, P. 2010. Commemoration of the war dead in Classical Athens: remembering defeat and victory. In: Pritchard, D.M. (Ed.). War, democracy and culture in Classical Athens. Cambridge University Press, Cambridge, 341-358.

Lüschen, G. 1970. The interdependence of sport and culture. In: Lüschen, G. (Ed.). The cross-cultural analysis of sport and games. Stipes Publishing Co., Champaign, 85-99.

Miller, S.G. 2004. Ancient Greek athletics. Yale University, New Haven.

Morley, N. 2004. Theories, models and concepts in ancient history. Psychology Press, London.

Nielsen, T.H. 2018. Two studies in the history of Ancient Greek athletics. The Royal Danish Academy of Sciences and Letters, Copenhagen. 
Osborne, R.G. 1993. Competitive festivals and the polis: a context for the dramatic festivals at Athens. In: Sommerstein, A.H. et al. (Eds.). Tragedy, comedy and the polis: papers from the Greek drama Conference Nottingham 18-20 July 1990. Levante Editori, Bari, 21-38.

Orwell, G. 1973. The sporting spirit. In: , eds. Orwell; S.; Angus, I. (Eds.). The collected essays, journalism and letters of George Orwell - volume IV: in front of your nose 1945-50. London: 40-4.

Pritchard, D.M. 1999. The fractured imaginary: popular thinking on citizen soldiers and warfare in fifth-century Athens. Tese de doutorado. Macquarie University, Sydney.

Pritchard, D.M. 2004. Kleisthenes, participation, and the dithyrambic contests of late archaic and Classical Athens. Phoenix 58: 208-228.

Pritchard, D.M. 2010. The symbiosis between democracy and war: the case of Ancient Athens. In: Pritchard. D.M. (Ed.). War, democracy and culture in Classical Athens. Cambridge University Press, Cambridge, 1-62.

Pritchard, D.M. 2012. Aristophanes and de Ste. Croix: the value of old comedy as evidence for Athenian popular culture. Antichthon 46: 14-51.

Pritchard, D.M. 2013. Sport, democracy and war in Classical Athens. Cambridge University Press, Cambridge.

Pritchard, D.M. 2015. Public spending and democracy in Classical Athens. University of Texas Press, Austin.

Pritchard, D.M. 2018. The standing of sailors in democratic Athens. DHA 44: 231-253.
Pritchard, D.M. 2019. Athenian democracy at war. Cambridge University Press, Cambridge.

Roisman, J. 2005. The rhetoric of manhood: masculinity and the attic orators. University of California Press, Berkeley.

Shear, J.L. 2001. Polis and Panathenaia: the history and development of Athena's Festival. Dissertação de mestrado. University of Pennsylvania, Philadelphia.

Shear, J.L. 2003. Prizes from Athens: the list of Panathenaic prizes and the sacred oil. ZPE 142: 87-105.

Singor, H.W. 2009. War and international relations. In: Raaflaub, K.A.; Wees, H. (Eds.). A companion to Archaic Greece (585-603). John Wiley \& Sons, New Jersey.

Sipes, R.G. 1973. War, sport and aggression. American Anthropologist 75: 64-86.

Sommerstein, A.H. 1996. How to avoid being a Komodoumenos. CQ 46: 327-356.

Vernant, J.P. 1988. Myth and society in Ancient Greece. Tradução: Janet Lloyd. Zone Books, New York.

Wilson, P. 2008. Costing the Dionysia. In: Revermann, M.; Wilson, P. (Eds.). Performance, iconography, reception: studies in honour of Oliver Taplin. Oxford University Press, Oxford, 88-127.

Zillmann, D.; Johnson, R.C.; Day, D.K. 1974. Provoked and unprovoked aggressiveness in athletics. Journal of Research in Personality 8: 139-152. 